\title{
Selective Deficits in Alzheimer and Parkinsonian Dementia: Visuospatial Function
}

\author{
Erich Mohr, Irene Litvan, Jill Williams, Paul Fedio and Thomas N. Chase
}

\begin{abstract}
Deficits in visuospatial cognition are frequently cited as an important component of the cognitive changes accompanying Parkinson's disease. To characterize possible differences between Parkinson's (PD) and Alzheimer's (AD) dementia, patients from both groups, matched for overall dementia severity, age and education, were contrasted neuropsychologically. Visuospatial tasks dissociated from memory, were significantly compromised in both patient groups. Differential impairment was evident on visuospatial abstraction and reasoning (Object Assembly), which was most deficient in PD. Visuospatial cognition associated with memory, classified both patient groups as impaired compared to controls, but AD patients demonstrated substantially lower performance levels than those with PD. Parkinsonian dementia thus appears to have some distinct features compared to Alzheimer's disease, which may indicate differences in underlying pathogenic mechanisms.
\end{abstract}

RÉSUMÉ: Déficits sélectifs dans la démence de la maladie d'Alzheimer et de la maladie de Parkinson: fonction visuospatiale Des déficits dans la cognition visuospatiale sont souvent cités comme étant une composante importante des changements cognitifs accompagnant la maladie de Parkinson. Afin de caractériser les différences possibles entre la démence de la maladie de Parkinson (MP) et celle de la maladie d'Alzheimer (MA), des patients de chacun de ces deux groupes, appariés pour la sévérité globale de la démence, l'âge et le niveau d'éducation, ont été comparés au point de vue neuropsychologique. Les tâches visuospatiales dissociées de la mémoire étaient significativement compromises dans les deux groupes de patients. Une atteinte différentielle était évidente au niveau de l'abstraction visuospatiale et du raisonnement (assemblage d'objets), cette atteinte étant plus marquée dans la MP. La cognition visuospatiale associée à la mémoire classifiait les deux groupes de patients comme atteints lorsqu'ils étaient comparés aux contrôles, mais les patients avec MA avaient des niveaux de performance plus bas que ceux des patients avec MP. La démence parkinsonienne semble donc posséder des caractéristiques distinctes comparativement à celles de la maladie d'Alzheimer, ce qui peut indiquer des différences sous-jacentes aux mécanisms pathogéniques.

Can. J. Neurol. Sci. 1990; 17:292-297

Intellectual deficits are now recognized as an important feature of Parkinson's disease. 1.2 .3 The incidence, severity and precise characteristics of the cognitive dysfunction, nevertheless, remains controversial. 1.4 .5 In particular, the question of a parkinsonian dementia, separate and distinct from the dementia of the Alzheimer-type, has been difficult to assess. Attempts to characterize parkinsonian dementia have included studies of neuropathological features, ${ }^{6-10}$ transmitter abnormalities,, 411 radiographic alterations, ${ }^{12}$ and neuropsychological changes. ${ }^{13}$ While certain relatively unique features of parkinsonian dementia have been ascertained (e.g. Lewy-body type cortical changes), ${ }^{6}$ it is unclear whether differences between Parkinson's and Alzheimer's dementia outweigh communalities.

Neurobehavioral investigations of Parkinson's disease have often focused on visuospatial cognition (e.g.). ${ }^{14}$ Although the idea of a generalized visuospatial deficit has been called into question, ${ }^{15}$ considerable evidence now suggests that circum- scribed aspects of these functions are indeed characteristically affected in parkinsonian patients. ${ }^{2}$ Furthermore, attenuated performance levels in visuospatial cognition have been reported both early in the disease process, ${ }^{2}$ as well as in high-functioning parkinsonian patients. ${ }^{16}$

Visuospatially mediated tasks were therefore chosen to further investigate the question of potential differences between Parkinson's and Alzheimer type dementia. To control for possible confounds, patients from both groups were matched for age, education and overall level of dementia (Mattis Dementia Rating Scale). ${ }^{17}$

\section{Methods}

Eleven demented patients (DSM III-R criteria ) ${ }^{18}$ with idiopathic Parkinson's disease, (10 men, 1 woman, mean $\pm S E M$ age $69 \pm 1.4$, range 59-76 years), 11 patients with Alzheimer's

From the Medical Neurology Branch (E.M., P.F.) and the Experimental Therapeutics Branch (I.L., J.W., T.N.C.), National Institute of Neurological Disorders and Stroke, Bethesda, MD

Received December 19, 1989. Accepted April 21, 1990

Reprint requests to: Dr. Erich Mohr, Royal Ottawa Hospital, Neuropsychology Service, 1145 Carling Avenue, Ottawa, Ontario K 1Z 7K4 
disease (DSM III-R ${ }^{18}$ and NINCDS-ADRDA criteria ), ${ }^{19} 5 \mathrm{men}$, 6 women, age $66 \pm 2.9$ ), and 11 neurologically normal control subjects ( 6 men, 5 women, mean age $66 \pm 1.8,56-73)$ were selected to participate in this study. All three study groups were matched for educational level (Table 1). Each consented to undergo all procedures after full disclosure of potential risks and benefits. Parkinsonian patients were maintained on optimal treatment with standard antiparkinsonian therapy, to minimize potential confounding of motor disability with results on cognitive testing. All patients with Alzheimer's disease had been free of centrally acting medications for at least 4 weeks prior to study onset.

Patients' accession criteria were arbitrarily set at a minimum Mattis Dementia Rating Scale score of 110, to insure adequate neuropsychological assessability and at a maximum of 136 , to allow for inclusion of mildly impaired individuals. As a result, both patient groups evidenced moderately advanced dementia (Parkinson's patients Mattis 125 $\pm 2.1,116-136$ and Alzheimer's patients $122 \pm 2.0,113-134)$ and were significantly impaired in comparison to controls $(143 \pm 0.5,140-144 ; p<.01)$.

Symptoms had been present in the parkinsonian group significantly longer than in the Alzheimer group (Table 1). Parkinson's patients had been treated with standard dopaminomimetic medication for $11 \pm 1.7$ (2-17) years, and had on the average moderate symptoms while medicated, with 1 patient in stage 2 and all remaining patients in stage 3 of the modified Hoehn and Yahr scale. ${ }^{20}$ Assessment of mood state (Hamilton Depression Inventory), ${ }^{21}$ revealed no statistically significant differences between the Parkinson's and Alzheimer's group.

All subjects received a complete psychometric assessment (Wechsler Adult Intelligence Scale-Revised, WAIS-R;22 and Wechsler Memory Scale) ${ }^{23}$ at the time of entry into this study. Visuospatial cognition and memory were evaluated with WAIS$R$ performance subscales and the visual reproduction subscale of the Wechsler Memory Scale. In addition the following neuropsychological tests were used to assess visuospatial function: Object Recognition and Placement (Pictorial Memory), ${ }^{24}$ where nine color photographs ( $3 \times 3$ geometric grid arrangement) are presented for 45 seconds and patients are asked to recall as many items as possible after removal of the plate. On the spatial memory portion of this test, patients are asked to indicate the location of each object on an identically arranged blank grid.
Mosaic Comparisons, ${ }^{25}$ measure patients' ability for detailed visuospatial discrimination by asking them to compare two $3 \times 3$ grids of square patterns, like those found on tiled walls or floors, which differ only in one of the 9 tiles; the column which contains the "different" tile has to be identified. The Street Map Test, ${ }^{26}$ examines the ability to discriminate between right and left turns in a direction away and toward the subject on a simulated map of a small town and the Rey-Osterrieth Complex Figure 27.28 tests copying skills of a complex figure with a subsequent free recall. Results of additional tests with emphasis on verbal cognition and memory have been reported elsewhere. ${ }^{30}$ The data were evaluated with Multivariate Analysis of Variance procedures. ${ }^{31}$

\section{Results}

Evaluation of overall intellectual status (Verbal, Performance and Full Scale IQ of the WAIS-R) attested to a substantial and comparable functional reduction in both patient groups $(\mathrm{p}<.01$; Table 1). Overall memory (Memory Quotient) was also deficient in both groups compared to controls $(p<.01)$ but evidenced a greater deficit for Alzheimer's compared to parkinsonian patients $(\mathrm{p}<.02$; Table 1).

Visuospatial cognition, not principally associated with memory (as measured by WAIS-R Performance subscales, Mosaic Comparison Test, Rey-Osterrieth Complex Figure-Copy), was significantly compromised in both patient groups compared to controls $(\mathrm{p}<.01$, Figure 1$)$. Performance differences between the 2 groups were limited to Object Assembly (WAIS-R Performance subscale), where parkinsonian patients showed a substantially greater deficit than those with Alzheimer's disease $(p<.05$, Figure 1). Analysis of process (time taken to complete the Object Assembly task, total number of pieces assembled, number of erroneous connections, differences as a function of design difficulty and contrast of number of perfectly assembled designs) failed to reveal any differences between demented Parkinsonians and Alzheimer's patients.

Visuospatial cognition with principal memory components (Visual Reproduction, Wechsler Memory Scale; Object Recognition and Placement; Rey-Osterrieth Complex Figure, 3 minute delayed recall; Street Map) was performed less well by both patient groups compared to controls $(p<.01)$. However, Alzheimer's patients tended to show relatively greater impair-

Table 1: Subject Characteristics.

\begin{tabular}{lccc}
\hline & $\begin{array}{c}\text { Normal } \\
\text { Controls }(\mathbf{N}=11)\end{array}$ & $\begin{array}{c}\text { Alzheimer's } \\
\text { Patients }(\mathbf{N}=11)\end{array}$ & $\begin{array}{c}\text { Parkinsonian } \\
\text { Patients }(\mathbf{N}=11)\end{array}$ \\
\hline $\begin{array}{l}\text { Education } \\
\text { Symptom Duration }\end{array}$ & $17 \pm 3.1(12-20)$ & $18 \pm 1.5(16-20)$ & $16 \pm 1.0(12-20)$ \\
Hoehn and Yahr Score & $5 \pm 1.0(1-10)^{* *}$ & $\begin{array}{c}13 \pm 4.7(6-18) \\
3 \pm 0.1(2-3)\end{array}$ \\
Wechsler Tests & & & \\
Verbal IQ & $128 \pm 2.8(108-144)$ & $97 \pm 3.4(79-123)^{+}$ & $98 \pm 2.3(86-111)^{+}$ \\
Performance IQ & $128 \pm 3.2(117-142)$ & $81 \pm 2.4(65-90)^{+}$ & $78 \pm 3.4(66-103)^{+}$ \\
Full Scale IQ & $132 \pm 2.9(120-148)$ & $89 \pm 2.5(80-109)^{+}$ & $93 \pm 5.0(81-133)^{+}$ \\
Memory Quotient & $137 \pm 3.3(110-143)$ & $76 \pm 2.8(64-93)^{+*}$ & $94 \pm 6.4(64-143)^{+}$ \\
\hline
\end{tabular}

+ Patients different from Normal Controls at $p<.01$.

* Alzheimer's patients different from parkinsonian patients at $p<.02$.

** Alzheimer's patients different from parkinsonian patients at $\mathrm{p}<.001$. 
ment levels on most of these tasks than parkinsonian patients. Object Recognition and Placement as well as the Street Map Test, were significantly less well performed by those with Alzheimer's disease ( $p<.05$, Figure 2). Delayed recall of the Rey-Osterrieth Complex Figure was borderline deficient in the Alzheimer's, compared to the parkinsonian patients $(\mathrm{p}<.07$, Figure 2).

\section{Discussion}

The present results showed characteristic differences in cognitive profiles between patients with Alzheimer's and Parkinson's disease, having equivalent degrees of overall intellectual dysfunction, confirming earlier observations in other cognitive realms. ${ }^{32}$

Visuospatial tasks not principally associated with memory, evidenced some differentiation between the two demented groups. Object Assembly, a visuospatially mediated task necessitating the ability to abstract from an incomplete stimulus and visuospatial reasoning, both skills which have been associated with frontal function, ${ }^{33}$ was significantly impaired in the Parkinsonians compared to controls as well as to Alzheimer's patients; the latter were also less proficient than controls. A comparison of the time taken to complete the task as well as additional task analysis, failed to reveal differences between the two groups, which strengthens the argument that visuospatial abstraction and reasoning abilities overall, rather than motor slowing or differential errors as a function of difficulty, were the source of observed differences. While this test's semantic memory component may have played a role in observed results, the remaining memory profile of the two patient groups would actually favor parkinsonians. It is therefore likely that the visuospatial abstraction and reasoning components of this test were the source of observed performance differences. However, these two patient groups failed to differ on Picture Arrangement, a test associated with sequential thinking and social sophistication, ${ }^{34}$ both of which may also be related to frontal lobe function. Nevertheless, Object Assembly and Picture Arrangement may use different "cognitive routines". While the former would appear to rely on the combination of visuospatial abstraction and reasoning, the latter necessitates principally social sophistication and reasoning. In as far as visuospatial cognition might be impaired in Parkinson's disease (e.g.), ${ }^{14}$ one might speculate that visuospatial abstraction is the most "vulnerable" of these tasks in the context of parkinsonian dementia and therefore the most likely to differentiate between the dementia subtypes under investigation here. In addition, Block Design, another timed

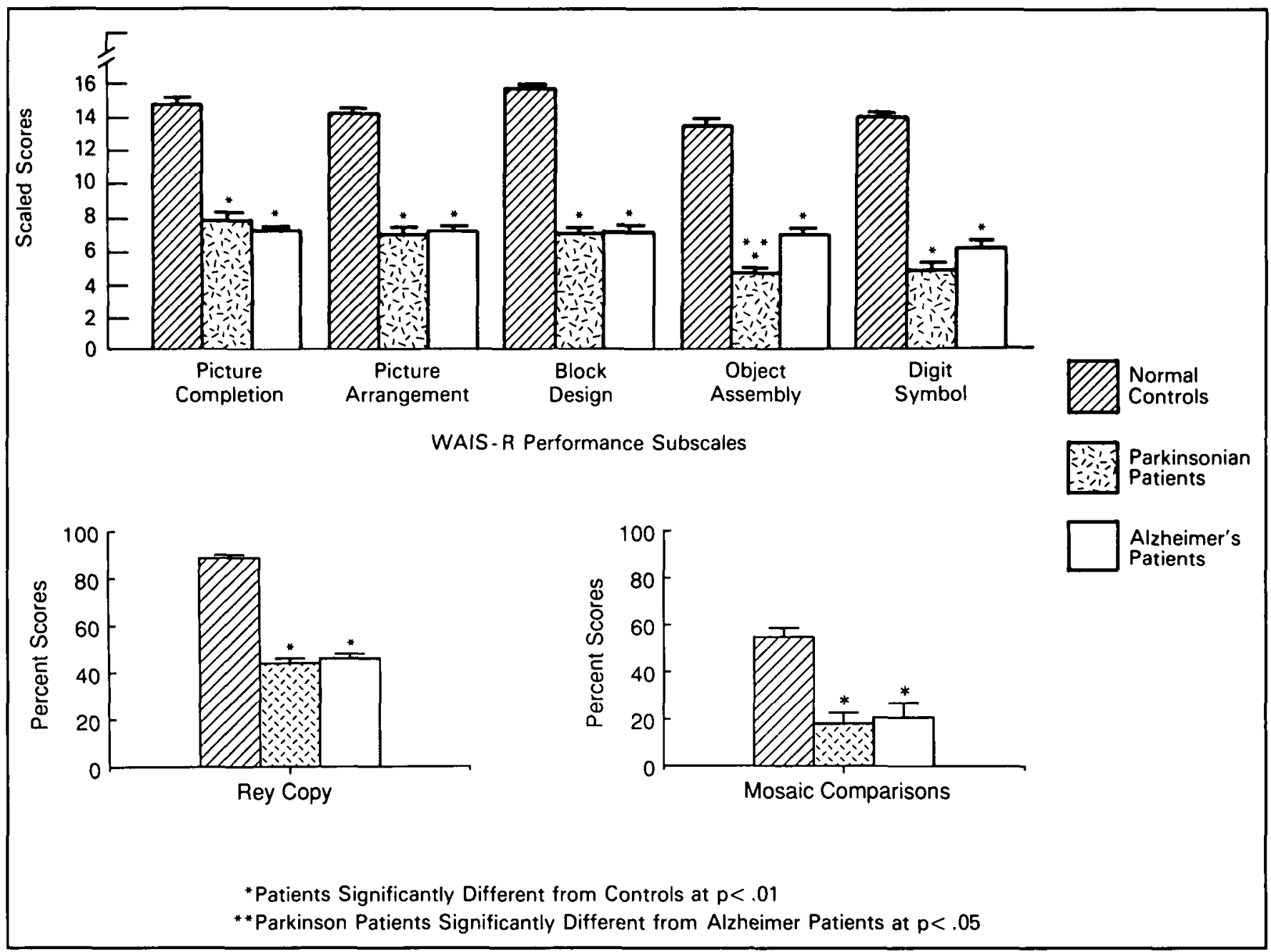

Figure I - Visuospatial cognition not principally associated with memory (Means $\pm S E M$ ). 


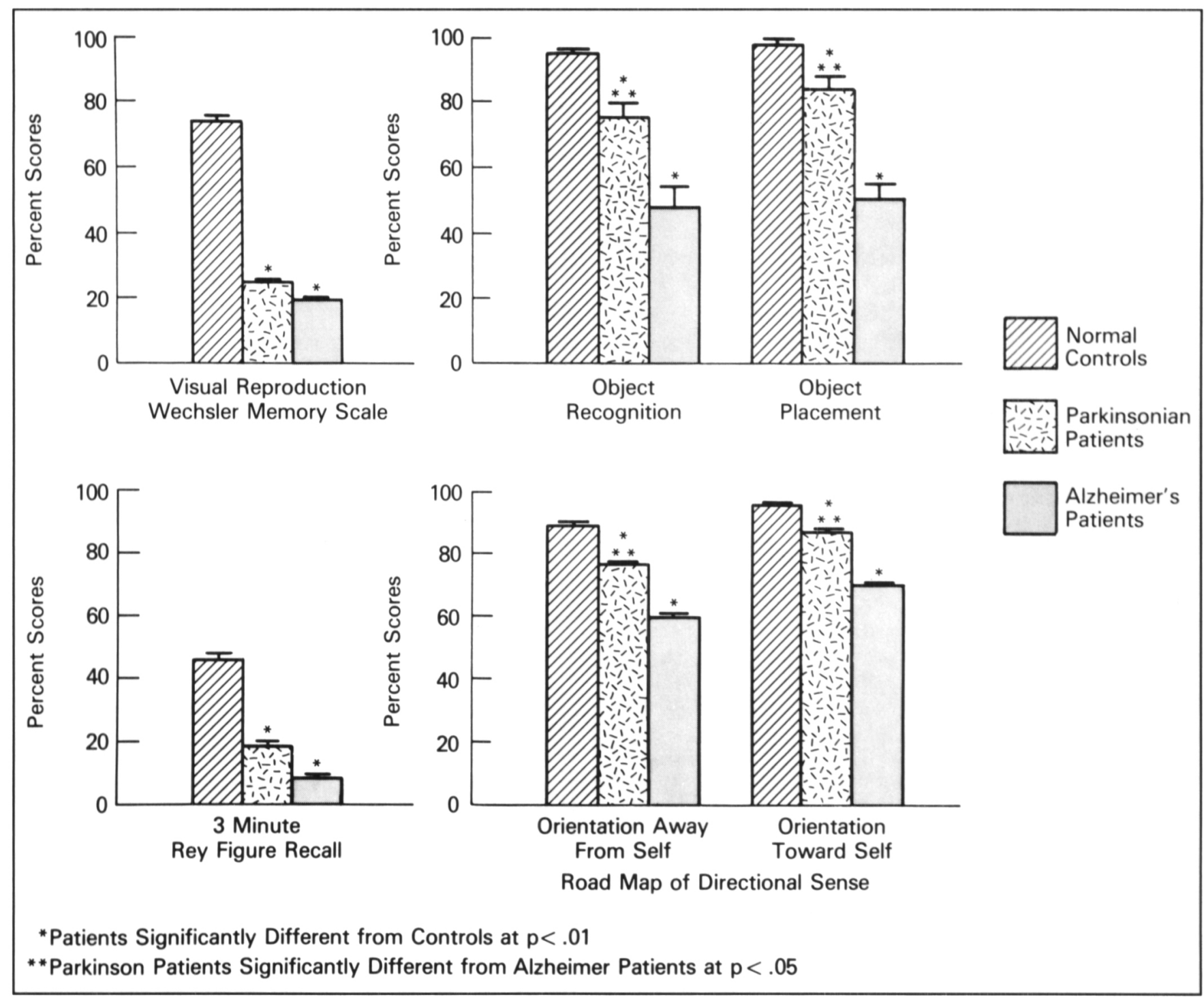

Figure 2 -Visuosparial tasks associated with memory (Means \pm SEM).

visuospatially mediated test, generally more associated with posterior dysfunction, ${ }^{34}$ was comparably performed by both patient groups. Since all of these tasks are timed, reduced speed is unlikely to account for these differential findings. The two other visuospatially mediated items without principal memory components (Rey-Osterrieth Complex Figure and Mosaic Comparisons), failed to differentiate between the two demented groups.

Visuospatial tasks with principal memory components classified Alzheimer's patients as more impaired than parkinsonian patients. This was true for overall memory function (Memory Quotient) in spite of comparable intellectual levels (Full Scale, Verbal and Performance IQs). Alzheimer's patients were more deficient regardless of which memory systems were tested (episodic memory, context bound knowledge ${ }^{35}$ such as the ReyOsterrieth Complex Figure, Recall, versus semantic memory, context-free, general principles ${ }^{35}$ like the Street Map). The relative failure of the Visual Reproduction subscale of the Wechsler Memory Scale to differentiate between the two groups, might be related to the potential motor disadvantage of parkinsonian patients in face of the graphic demands of this task, as well as item complexity. Recall of simple geometric figures (Visual Reproduction) may not have taxed memory sufficiently, while recall of the complex Rey-Osterrieth Figure, in spite of graphic motor demands on the Parkinsonians, tended to classify Alzheimer's patients as relatively more impaired than those with Parkinson's disease.

Neuroanatomical evidence may help explain the observed double dissociation between performance on Object Assembly (a visuospatially mediated task of abstraction and reasoning, where Parkinsonians evidenced the relatively greatest deficit) and visuospatial memory (where Alzheimer's patients were least accurate). Frontal deficits appear to be a consistent feature of Parkinson's disease. ${ }^{36}$ Preclinical evidence with primates implicates a loss of striatal-frontal connectivity 37 in these impairments, likely one of the pathognomonic aspects of Parkinson's disease. The frontal deficits noted in Alzheimer's patients, although milder than in Parkinsonians, may be indicative of frontal cortical involvement, observable in some individuals with Alzheimer's disease. ${ }^{38.39}$ Differential spatial memory 
deficits in the two groups, might reflect the well established involvement of septo-hippocampal systems in Alzheimer's patients; ${ }^{4}$ while Alzheimer-type changes in the septo-hippocampal system are reported to occur in demented parkinsonian patients, ${ }^{10}$ they are not always evident. ${ }^{9}$ The observed milder impairments in Parkinson's patients may alternatively implicate dorsolateral striatal-frontal connections, which have tentatively been linked to spatial memory. ${ }^{37}$

Both communalities and differences in these two dementia groups might also be related to characteristic neurotransmitter abnormalities. While a whole host of transmitter deficits are implicated in both disorders, ${ }^{4}$ their relative contribution may be of importance. The deficit in dopaminergic neural transmission is the central contributor to parkinsonian motor symptoms, and may play some limited role in cognition. ${ }^{3,40}$ The functional role of dopamine in Alzheimer's disease is less secure and earlier attempts of palliative treatment with L-Dopa failed to yield encouraging results. ${ }^{41}$ Cortical noradrenergic deficiencies, on the other hand, are more common to both groups.4,42-45 Deficits in this system, which has been associated with learning and memory, ${ }^{46-48}$ could thus be a necessary but not sufficient condition for dementing symptoms. Compromises in cholinergic function, one of the central neurotransmitter deficits in Alzheimer's disease, ${ }^{49,50}$ have also been observed in Parkinson's disease, ${ }^{9}$ but do not appear to be a consistent feature. ${ }^{4}$ While the complexities of transmitter involvement in the primary degenerative dementias make conclusions difficult, 51 a more catecholamine based dementia in Parkinson's disease, compared to a more acetylcholine related dementia in Alzheimer disease, might account for some of the neurobehavioral differences observed here.

Parkinson's and Alzheimer's patients matched for overall level of dementia evidenced certain communalities in neurobehavioral deficits. Nevertheless, the important differences in profiles observed here, mainly the dissociation between visuospatial cognition involving abstraction versus memory-related function in the 2 disorders, point to differences in the underlying dementing process from Alzheimer's disease in the majority of parkinsonian patients in the present study. Reports of multiple pathophysiological profiles in demented Parkinsonians, however, caution against simplistic interpretations.

\section{REFERENCES}

I. Brown RG, Marsden CD. "Subcortical dementia": the neuropsychological evidence. Neuroscience 1988; 25: 363-387.

2. Sahakian BJ, Morris RG, Evenden JL, et al. A comparative study of visuospatial memory and learning in Alzheimer-type dementia and Parkinson's disease. Brain 1988; 111: 695-718.

3. Mohr E, Fabbrini G, Williams J, et al. Dopamine and memory function in Parkinson's disease. Movement Disorders 1989; 4 113-120.

4. Agid Y, Ruberg M, Dubois B, et al. Parkinson's disease and dementia. Clin Neuropharmacol 1986; 9: S22-S36.

5. Teraevaeinen $\mathrm{H}$, Hietanen $\mathrm{M}$, Stoessl J, et al. Dementia in movement disorders. Can J Neurol Sci 1986; 13: 546-558.

6. Alvord EC, Forno LS, Kusske JA, et al. The pathology of parkinsonism: a comparison of degenerations in the cerebral cortex and brain stem. Adv Neurol 1974; 5: 175-193.

7. Hakim AM, Mathieson G. Dementia in Parkinson's disease: a neuropathologic study. Neurology 1979; 29: 1209-1214.

8. Boller F, Mizutani T, Roessmann U, et al. Parkinson disease, dementia and Alzheimer's disease: clinicopathologic correlates. Ann Neurol 1980; 7: 329-335.
9. Chui CH, Mortimer JA, Slager U, et al. Pathologic correlates of dementia in Parkinson's disease. Arch Neurol 1986; 43: 991995.

10. Jellinger K. Neuropathological substrates of Alzheimer's disease and Parkinson's disease. J Neural Transm 1987; 24: 109-129.

11. Dubois B, Danze F, Pillon B, et al. Cholinergic-dependent cognitive deficits in Parkinson's disease. Ann Neurol 1987; 22: 26-30.

12. Lichter DG, Corbett AJ, Fitzgibbon GM, et al. Cognitive and motor dysfunction in Parkinson's disease. Clinical, performance and computed tomographic correlations. Arch Neurol 1988; 45: 854860.

13. Huber SJ, Shuttleworth EC, Paulson GW. Dementia in Parkinson's disease. Arch Neurol 1986; 43: 987-990.

14. Boller F, Passafiume D, Keefe NC, et al. Visuospatial impairment in Parkinson's disease: the role of perceptual and motor factors. Arch Neurol 1984; 41 : 485-490.

15. Brown RG, Marsden CD. Visuospatial function in Parkinson's disease. Brain 1986; 109: 987-1002.

16. Mohr E, Juncos J, Cox C, et al. Selective deficits in cognition and memory in high-functioning Parkinsonian patients. J Neurol Neurosurg Psychiatry; in press.

17. Mattis $S$. Mental status examination for organic mental syndrome in the elderly. In: Bellack L, Karasu TB, eds. Geriatric Psychiatry. New York: Grune and Stratton 1976; 77-121.

18. American Psychiatric Association. Diagnostic and statistical manual of mental disorders. American Psychiatric Association 1987. Third ed. revised. Washington, D.C

19. McKhann G, Drachman D, Folstein M, et al. Clinical diagnosis of Alzheimer's disease: report of the NINCDS-ADRDA work group under the auspice of Department of Health and Human Services task force on Alzheimer's disease. Neurology 1984; 34: 939-944.

20. Fahn S, Marsden CD, Calne D, et al. Recent developments in Parkinson's disease. New Jersey, Macmillan Health Care Information 1987; 293-304.

21. Hamilton M. A rating scale for depression. J Neurol Neurosurg Psychiatry 1960; 23: 56-62.

22. Wechsler D. Wechsler Adult Intelligence Scale-Revised. New York, The Psychological Corporation 1981.

23. Wechsler D, Stone CP. Wechsler Memory Scale. New York, The Psychological Corporation 1945.

24. Bruno G, Mohr E, Gillespie M, et al. Muscarinic agonist therapy of Alzheimer's disease: a clinical trial of RS-86. Arch Neurol 1986; 43: 659-661.

25. Brouwers P, Cox C, Martin A, et al. Differential perceptual spatial impairment in Huntington's and Alzheimer's dementias. Arch Neurol 1984; 41: 1073-1076.

26. Money JA. Standardized Road Map of Direction Sense. San Rafael California: Academic Therapy Publications 1976.

27. Rey A. L'examen psychologique dans le cas d'encephalopathie traumatique. Archives de Psychologie 1941; 28: 286-340.

28. Osterrieth PA. Le test de copie d'une figure complexe: contribution l'etude de la perception et de la memoire. Archives de Psychologie 1944; 30: 206-356.

29. Heaton R. Wisconsin Card Sorting Test Manual. Odessa, Florida, Psychological Assessment Resources 1981.

30. Litvan I, Mohr E, Williams J, et al. Differential memory and executive functions in demented patients with Parkinson's and Alzheimer disease. Journal Neurol Neurosurg Psychiatry; in press.

31. Brown MD, Engelman L, Frane JW, et al. BMDP Statistical Software, Los Angeles, University of California 1985; 59-412.

32. Cummings JL, Darkins A, Mendez M, et al. Alzheimer's disease and Parkinson's disease: comparison of speech and language alterations. Neurology 1988; 38: 680-684.

33. Stuss DT, Benson DF. The frontal lobes. New York: Raven Press, 1986

34. Lezak MD. Neuropsychological assessment, second edition. New York: Oxford University Press, 1983; 280-283.

35. Squire LR, Cohen NJ. Human memory and amnesia. In: Lynch G, McGaugh JL, Weinberger NM, eds. Neurobiology of learning and memory. New York: Guilford Press, 1984; 40. 
36. Gotham AM, Brown RG, Marsden CD. 'Frontal' cognitive function in patients with Parkinson's disease 'on' and 'off' levodopa. Brain 1988; 111: 299-321.

37. Alexander GE, DeLong MR, Strick PL. Parallel organization of functionally segregated circuits linking basal ganglia and cortex. Ann Rev Neurosci 1986; 9: 357-81.

38. Chase TN, Burrows GH, Mohr E. Cortical glucose utilization patterns in primary degenerative dementias of the anterior and posterior type. Arch Gerontol Geriatr 1987; 6: 289-97.

39. Mann UM, Mohr E, Chase TN. Rapidly progressive Alzheimer's disease. The Lancet; 1989; 2: 799.

40. Mohr E, Fabbrini G, Ruggieri S, et al. Cognitive concomitants of dopamine system stimulation in Parkinsonian patients. J Neurol Neurosurg Psychiatry 1987; 50: 1192-1196.

41. Ferris S, Reisberg B, Crook T, et al. Pharmacologic treatment of senile dementia: choline, L-Dopa, piracetam and choline plus piracetam. In: Corkin S, Davis K, Growden J, Usdin E, Wurtman R, eds. Alzheimer's disease: a report of progress. New York: Raven Press, 1982.

42. Adolfsson R, Gottfries CG, Roos BE, et al. Changes in brain catecholamines in patients with dementia of Alzheimer type. Brit J Psychiat 1979; 135: 216-23.

43. Perry EK, Tomlinson BE, Blessed G, et al. Neuropathological and biochemical observations on the noradrenergic system in Alzheimer's disease. J Neurol Sci 1981; 51: 279-287.
44. Rossor M, Iversen LL. Non-cholinergic neurotransmitter abnormalities in Alzheimer's disease. Br Med Bull 1986; 42: 70-74.

45. Cash R, Dennis T, L'Heureux R, et al. Parkinson's disease and dementia: norepinephrine and dopamine in locus ceruleus. Neurology 1987; 37: 42-46.

46. Randt CT, Quartermain D, Goldstein M, et al. Norepinephrine biosynthesis inhibition: effects on memory in mice. Science 1971; 172: 498-9.

47. Kety SS. The possible role of the adrenergic systems of the cortex in learning. Res Publ Assoc Res Nerv Ment Dis 1972; 50: 37689.

48. Stein L, Belluzzi JD, Wise CD. Memory enhancement by central administration of norepinephrine. Brain Res 1975; 84: 329-35.

49. Perry EK, Tomlinson BE, Blessed G, et al. Correlation of cholinergic abnormalities with senile plaques and mental test scores in senile dementia. Br Med J 1978; 2: 1457-1459.

50. Perry EK. The cholinergic hypothesis - ten years on. Br Med Bull 1986; 42: 63-69.

51. Mohr E, Chase TN. Treatment stategies in primary degenerative dementias. In: Boller, F., Grafman J. eds. Handbook of Neuropsychology, Volume 5: Aging and Dementia. Amsterdam: Elsevier, 1990; in press. 